\title{
Vaccines for the elderly: current use and future challenges
}

\author{
Birgit Weinberger(D)
}

\begin{abstract}
Age-related changes of the immune system contribute to increased incidence and severity of infections in the elderly. Vaccination is the most effective measure to prevent infections and vaccination recommendations in most countries include specific guidelines for the elderly. Vaccination against influenza and Streptococcus pneumoniae is usually recommended for persons with underlying diseases and for the elderly with heterogeneous age limits between $\geq 50$ years and $\geq 65$ years. Some countries also recommend vaccination against herpes zoster. Several vaccines are recommended for all adults, such as regular booster shots against tetanus/diphtheria/pertussis/polio, or for specific groups, e.g. vaccination against tick-borne encephalitis in endemic areas or travel vaccines. These are also relevant for the elderly. Most currently used vaccines are less immunogenic and effective in the elderly compared to younger adults. Potential strategies to improve their immunogenicity include higher antigen dose, alternative routes of administration, and the use of adjuvants, which were all implemented for influenza vaccines, and induce moderately higher antibody concentrations. Research on universal vaccines against influenza and S. pneumoniae is ongoing in order to overcome the limitations of the current strain-specific vaccines. Respiratory syncytial virus causes significant morbidity in the elderly. Novel vaccines against this and other pathogens, for instance bacterial nosocomial infections, have tremendous potential impact on health in old age and are intensively studied by many academic and commercial organizations. In addition to novel vaccine developments, it is crucial to increase awareness for the importance of vaccination beyond the pediatric setting, as vaccination coverage is still far from optimal for the older population.
\end{abstract}

Keywords: Vaccine, Elderly, Aging, Immunosenescence, Influenza, Herpes zoster, Streptococcus Pneumoniae

\section{Background}

With increasing life expectancy, the global population ages, and the number of persons older than 60 years of age is expected to double by 2050, reaching 2.1 billion. The number of persons above 80 years is projected to increase even more dramatically from a worldwide total of 125 million in 2015 to 434 million in 2050 [1]. The severity of many infections is higher in the elderly compared to younger adults and infectious diseases are frequently associated with long-term sequelae such as impairments in activities of daily living, onset of frailty, or the loss of independence [2,3]. This represents a serious challenge for public health systems, and the prevention of infectious disease is therefore an important measure to ensure healthy aging and improve the quality of life. The tremendous success of childhood vaccination is widely

Correspondence: birgit.weinberger@uibk.ac.at

Universität Innsbruck, Institute for Biomedical Aging Research, Rennweg 10, 6020 Innsbruck, Austria recognized, but the need for life-long vaccination programs and the importance of vaccination for the older population are frequently underestimated. This review summarizes current recommendations for developed countries, gives examples regarding immunogenicity and efficacy data for vaccines currently used for the elderly, and provides an outlook on novel vaccines developed specifically for this age group.

\section{Vaccines specifically recommended for the elderly} Many countries have established vaccination recommendations for adults and most of these also include specific guidelines for older adults. Vaccination against influenza and Streptococcus pneumoniae is usually recommended for persons with underlying diseases and for the elderly with heterogeneous age limits between $\geq 50$ years and $\geq 65$ years. Some countries also recommend vaccination against herpes zoster for older adults. Table 1 summarizes current recommendations for Europe and the USA $[4,5]$. 
Table 1 Vaccination recommendations for older adults in Europe and the US

\begin{tabular}{|c|c|c|c|c|c|c|}
\hline & Influenza ${ }^{a}$ & S. pneumoniae ${ }^{\text {b }}$ & Herpes zoster $^{d}$ & Tetanus & Diphtheria $^{i}$ & Pertussisj \\
\hline Austria & all adults & $>50 ; P C V+P P V^{c}$ & $>50$ & every 5 years ${ }^{\mathrm{e}}$ & every 5 years ${ }^{\mathrm{e}}$ & every 5 years ${ }^{\mathrm{e}}$ \\
\hline Belgium & $>65$ & $>65 ; P C V+P P V^{c}$ & & every 10 years & every 10 years & once $^{h}$ \\
\hline Bulgaria & $>65$ & - & - & every 10 years & every 10 years & - \\
\hline Croatia & $>65$ & - & & once at 60 & - & - \\
\hline Cyprus & $>65$ & $>65 ;$ PPV & & every 10 years & every 10 years & - \\
\hline Czech Rep. & all adults & $>65 ; P C V+P^{P P V}$ & $>50$ & every 10 years $^{f}$ & - & once at 65 \\
\hline Denmark & $>65$ & $>65 ; \mathrm{PCV}$ or PPV & & - & - & - \\
\hline Estonia & $>65$ & - & & every 10 years & every 10 years & - \\
\hline Finland & $>65$ & $>65 ; \mathrm{PCV}$ or PPV & & every 10 years & every 10 years & - \\
\hline France & $>65$ & - & $65-75$ & every 10 years $^{9}$ & every 10 years $^{9}$ & once $^{h}$ \\
\hline Germany & $>60$ & $>60 ; \mathrm{PPV}$ & & every 10 years & every 10 years & once $^{h}$ \\
\hline Greece & $>60$ & $>65 ;$ PCV & $>60$ & every 10 years & every 10 years & once $^{\text {h }}$ \\
\hline Hungary & $>60$ & > 50; PPV & & - & - & - \\
\hline Iceland & $>60$ & $>60 ; \mathrm{PPV}$ & & - & - & - \\
\hline Ireland & $>65$ & $>65 ;$ PPV & & - & - & - \\
\hline Italy & $>65$ & $>65 ; P C V+P P V^{c}$ & $>65$ & every 10 years & every 10 years & every 10 years \\
\hline Latvia & $>65$ & - & & every 10 years & every 10 years & - \\
\hline Liechtenstein & $>65$ & - & & every 10 years $^{9}$ & every 10 years $^{9}$ & every 10 years $^{\mathrm{g}}$ \\
\hline Lithuania & $>65$ & - & & every $5-10$ years & every 5-10 years & - \\
\hline Luxembourg & $>65$ & $>60 ; P C V+P P V^{c}$ & & every 10 years & every 10 years & every 10 years \\
\hline Malta & all adults & $>65 ; \mathrm{PCV}$ & & - & - & - \\
\hline Netherlands & $>60$ & - & & - & - & - \\
\hline Norway & $>65$ & $>65 ;$ PPV & & - & - & - \\
\hline Poland & all adults & > 50; PCV & & once $^{h}$ & once $^{h}$ & - \\
\hline Portugal & $>65$ & - & & every 10 years $^{9}$ & every 10 years $^{9}$ & - \\
\hline Romania & $>65$ & - & & - & - & - \\
\hline Slovakia & $>60$ & $>60 ; \mathrm{PCV}$ & & every 15 years & every 15 years & - \\
\hline Slovenia & all adults & $>65: P C V$ or PPV & & every 10 years & every 10 years & once $^{h}$ \\
\hline Spain & $>65$ & $>65 ; \mathrm{PPV}$ & & once at 65 & once at 65 & - \\
\hline Sweden & - & $>65 ;$ PPV & & every 20 years & every 20 years & - \\
\hline UK & $>65$ & $>65 ; \mathrm{PPV}$ & $>70$ & - & - & - \\
\hline USA & all adults & $>65 ; P C V+P P V^{c}$ & $>60$ & every 10 years & every 10 years & once $^{h}$ \\
\hline
\end{tabular}

Shown are recommendations for the general population for all countries listed by the European Centre for Disease Prevention and Control. Specific recommendations for risk groups (co-morbidities, health care personnel etc.) are available in most countries

annual vaccination, inactivated trivalent vaccine

${ }^{b}$ recommendation for persons without prior vaccination against pneumococcal disease; no booster shots recommended for general population; recommendations may differ for persons with underlying medical conditions

cone dose of PCV13 (pneumococcal conjugate vaccine) followed by 1 dose of PPV23 (pneumococcal polysaccharide vaccine)

${ }^{d}$ one dose, contraindicated in immunosuppressed patients (live vaccine)

${ }^{e}$ for persons over 65 years; every 10 years for younger adults

for persons over 65 years; every 10-15 years for younger adults

${ }^{g}$ for persons over 65 years; every 20 years for younger adults

honce during adulthood

'vaccine containing reduced diphtheria dose (d)

${ }^{j}$ vaccine containing acellular pertussis antigens

\section{Influenza}

Influenza causes approximately 100,000 hospitalizations and 36,000 deaths annually in the USA, which occur mainly in persons over the age 65 years $[6,7]$. Vaccines against influenza usually contain three different strains $(\mathrm{A} / \mathrm{H} 1 \mathrm{~N} 1, \mathrm{~A} / \mathrm{H} 3 \mathrm{~N} 2, \mathrm{~B})$ and the exact composition of the vaccine is determined each year by the World Health Organization (WHO) based on surveillance data. 
Recently, quadrivalent vaccines became available, as two different B strains had circulated in parallel for several years $[8,9]$. Annual vaccination against influenza is recommended, as the composition of the vaccine changes in order to reflect currently circulating virus strains.

Immunogenicity of influenza vaccines is usually measured by hemagglutination inhibition assay (HAI), which quantifies antibodies specific for the viral hemagglutinin. Many studies demonstrated that antibody concentrations after vaccination are lower in older compared to younger adults [10] and that co-morbidities and frailty further decrease responsiveness to vaccination [11, 12]. Clinical efficacy or effectiveness of influenza vaccines is difficult to analyze, as compilations of results from clinical studies are highly complex. Parameters such as study population (age distribution, co-morbidities, frailty etc.), epidemiological factors (transmission patterns e.g. in institutionalized cohorts, prevalence of the virus), and virological factors (virulence, mismatch between vaccine and circulating viral strains) are different for each study and each influenza season. In addition, various clinical read-out parameters for influenza disease such as influenza-like illness (ILI), laboratory confirmed influenza or hospitalization due to influenza are utilized. Meta-analyses have estimated clinical benefits of influenza vaccination, and it can be concluded that protection is lower in older than in young adults $[13,14]$. Several strategies to improve influenza vaccines for the elderly led to the licensure of vaccines containing the oil-in-water emulsion adjuvant MF59 [15] or $60 \mu \mathrm{g}$ instead of $15 \mu \mathrm{g}$ of hemagglutinin protein per dose [16], and of a vaccine administered via the intradermal instead of the intramuscular route [17]. These vaccines elicit slightly higher antibody responses compared to the standard inactivated vaccine. Interestingly, MF59-adjuvanted vaccines induce substantially higher antibody responses against heterologous vaccine strains $[18,19]$, and this broader neutralizing activity probably contributes to the higher clinical efficacy observed with the adjuvanted vaccine. A large trial in Italy demonstrated that the risk of hospitalization for influenza or pneumonia was $25 \%$ lower for the adjuvanted vaccine compared to non-adjuvanted vaccine (relative risk 0.75 , 95\% CI 0.57 0.98) [20]. In a study including residents of long-term care facilities, the risk of ILI was higher in persons receiving standard TIV (OR 1.52, 95\% CI 1.22-1.88) than in those who had received the adjuvanted vaccine. This effect was even more pronounced in patients with respiratory and cardiovascular disease [21].

\section{Pneumococcal disease}

Invasive pneumococcal disease (bacteremia, meningitis etc.) mainly affects young children and older adults [22, 23]. S. pneumoniae is also a common cause of communityacquired pneumonia (CAP) in the elderly [24]. A 23-valent polysaccharide vaccine has been used for many years for older adults, but polysaccharides induce IgM-dominated antibody responses without adequate immunological memory, as they are $\mathrm{T}$ cell-independent antigens. Conjugated vaccines have been developed for the vaccination of infants and very successfully reduced the burden of disease in children. A 13-valent conjugate vaccine has been introduced also for older adults. In a large randomized trial in persons over 65 years of age it was demonstrated that 45.6\% (95.2\% CI 21.8-62.5, $p<0.001)$ fewer first episodes of vaccine-type CAP requiring hospitalization and $75.0 \%$ (95\% CI 41.4-90.8, $p<0.001$ ) fewer first episodes of vaccine-type invasive pneumococcal disease occurred in the vaccine group compared to placebo [25]. Vaccination recommendations for S. pneumoniae are heterogeneous. Some countries still recommend the polysaccharide vaccine, while others recommend the conjugate vaccine alone or followed by the polysaccharide vaccine usually at least one year later. Details regarding the recommendations in European countries are published by the European Centre of Disease Prevention and Control. With the introduction of a 7-valent and a 10-valent conjugate vaccine for childhood vaccination around the year 2000 disease incidence and carriage of the serotypes included in the vaccines decreased in children. Consequently, transmission of these serotypes to older adults and therefore disease incidence in the older age group also decreased in the following years. However, serotype replacement was observed, which means that the incidence of pneumococcal disease caused by other serotypes, not included in the conjugated vaccines, increased both in children and older adults [26-28]. Similar effects have been observed for the 13-valent vaccine [29-31].

\section{Herpes zoster}

Almost all adults are latently infected with varicella zoster virus (VZV). The primary infection, which usually occurs in childhood, manifests as chickenpox and live-long latency is established afterwards. Partial reactivation of the virus probably occurs frequently throughout life, but is usually controlled by virus-specific $\mathrm{T}$ cell responses. In the absence of sufficient immunological control, e.g. due to immunosuppression or immunosenescence, viral reactivation can lead to herpes zoster (shingles) [32]. The incidence of herpes zoster increases with age and it has been estimated that up to $50 \%$ of all cases affect persons older than 85 years [33, 34]. In a fraction of the patients acute episodes of herpes zoster are followed by post-herpetic neuralgia (PHN), characterized by long-lasting severe pain after the resolution of the zoster rash. The incidence of this complication is higher in older zoster patients, where it occurs in approximately one third of the cases [35]. Particularly in older patients, PHN frequently leads to substantial impairment in activities of daily living or even loss 
of independence [36, 37]. A single-shot immunization with an attenuated live-vaccine against herpes zoster, which has been licensed for use in older adults in 2006, is recommended in some countries. This vaccine induces $\mathrm{T}$ cell and antibody responses [38]. It was shown to reduce the incidence of herpes zoster by $51.3 \%$ (95\% CI $44.2-$ 57.6) and the incidence of PHN by $66.5 \%$ (95\% CI $44.5-$ 79.2) compared to placebo in a large randomized trial including persons older than 60 years [39]. The protective effect of the vaccine was lower in the very old, and longterm follow-up studies showed that protection waned over time, dropping to $21.1 \%$ (95\% CI 20.9-30.4) for the prevention of herpes zoster and 35.4\% (95\% CI 8.8-55.8\%) for PHN in years 7-10 [40, 41]. Antibody responses to a second dose of the vaccine more than 10 years after the first dose were similar to the first response, but cellular immune responses were higher after the booster dose. These findings indicate that there was a residual effect of the first vaccination on cellular immunity more than 10 years later and that the second dose induced a booster response [42]. Repeated vaccination of older individuals at appropriate intervals could therefore be considered for future recommendations.

\section{Vaccines recommended for all adults}

Regular booster vaccinations against tetanus and diphtheria, in some cases combined with pertussis and/or polio, are recommended in many countries for all adults, including the elderly (summarized in Table 1). Regular vaccination against other pathogens is recommended in some countries, e.g. against tick-borne encephalitis in endemic areas. Most countries do not have specific recommendations for older adults, but e.g. in Austria, France, Liechtenstein and Portugal booster intervals are shortened for persons over 65 years.

\section{Tetanus and diphtheria}

Tetanus- and diphtheria-specific antibody concentrations are frequently below the levels considered to be protective for adults, and are even lower for the elderly [43-48]. We could show that approximately $10 \%$ of a healthy elderly cohort recruited in Austria did not develop protective antibodies against diphtheria after a single booster shot and that almost half of the participants did not have antibodies above protective levels 5 years later. A second booster shot at this time point did again not provide long-term protection $[48,49]$. This could be due to insufficient priming earlier in life, inadequate boosters throughout adulthood or age-related defects of the immune system. Given the fact that tetanus-specific antibody concentrations were substantially higher in the same cohort, one could also speculate that the currently used combination vaccine, which contains a reduced amount of diphtheria toxoid, might not be optimal. A more detailed overview of tetanus and diphtheria vaccination of the elderly has recently been published [50]. Antibody responses to booster vaccination against tick-borne encephalitis are also lower in old compared to young adults $[51,52]$.

\section{Pertussis}

Vaccination against pertussis is widely used and accepted in the pediatric setting, but epidemiological data show an increased incidence of pertussis in adults and particularly in the elderly, for whom the infection can be associated with severe symptoms and increased mortality [53-55]. Adults can also transmit the disease to newborn infants, who are too young to be vaccinated. Few countries recommend regular booster immunizations with combined vaccines containing tetanus, diphtheria and pertussis antigens, whereas some recommend only one dose of pertussiscontaining vaccine during adulthood. Many countries, however, do not recommend booster vaccination against pertussis for adults. Booster doses of combined tetanus/ diphtheria/pertussis vaccine are well tolerated and immunogenic when given periodically to young or older adults [56], but antibody concentrations 4 weeks after vaccination are lower in old compared to young adults [46].

Appropriate vaccination documentation is crucial to deliver booster vaccinations at the right time points. Unfortunately, this documentation is often fragmentary for older adults, and it is therefore difficult to reliably assess adequate primary vaccination in childhood and the number of booster immunizations received throughout life. Several studies on tetanus/diphtheria vaccination reported only incomplete immunization histories $[45,47,48]$. Launay et al. reported that the number of vaccine doses received in life decreases from 7.1 (95\% CI 6.9-7.2) doses of tetanus vaccine in young adults, which corresponds well with recommendations of 5 doses during childhood/adolescence and 10 year-booster intervals afterwards, to only 5.7 (95\% CI 4.6-6.8) doses for adults aged 50-60 years [47]. This indicates a lack of regular booster immunizations during adulthood for this age group. Vaccination strategies for the future should include regular and well-documented booster shots throughout life, as post-booster antibody concentrations correlate with pre-booster antibody concentrations [46].

\section{Travel vaccines}

Travel vaccines are becoming more important for older adults, as the number of older long-distance travelers increases due to improved health and mobility of this age group. Incidence and severity of typhoid fever and Japanese encephalitis are higher in older compared to younger adults $[57,58]$, highlighting the importance of travel vaccines for this age group. Vaccines against typhoid fever, Japanese encephalitis, rabies or yellow fever are 
neo-antigens for most older travelers and many older adults probably also never had contact with Hepatitis A and Hepatitis B. One hallmark of immunosenescence is the loss of naïve $T$ cells and to a lesser extent of naïve $B$ cells, which affects primary immune responses to these antigens. Impaired memory generation late in life has been demonstrated in animal models $[59,60]$ and therefore the success of primary vaccination late in life might be limited. Unfortunately, very few data are available regarding immune responses of the elderly to travel vaccines as most studies exclude older participants. Therefore, immunization guidelines rely primarily on studies with young adults. Antibody responses to Hepatitis $\mathrm{A}$ and $\mathrm{B}$ vaccines are already reduced in middleaged adults compared to younger age groups [61, 62] and the percentage of non-responders without protective antibody concentrations against Hepatitis B increases with age [63]. Vaccination against Hepatitis B is not only relevant for older travels, but also for other risk groups, such as health care workers, household contacts of infected persons and hemodialysis patients, which also include older persons. Vaccination against yellow fever is mandatory for travelers to some South American and African countries. The live-attenuated yellow fever vaccine is highly immunogenic, but meta-analysis indicates that older adults have a higher risk for rare severe adverse events, such as e.g. yellow fever vaccineassociated viscerotropic disease, which mimics infection with the wild-type virus and has a high mortality of up to $60 \%$ [64].

\section{New vaccines developed for the elderly Next-generation vaccines against influenza, pneumococcal disease and herpes zoster}

The current vaccines against influenza, S. pneumoniae and herpes zoster have several limitations. Vaccination against influenza has to be administered annually, as the vaccine provides protection only against the strains included in the formulation or closely related variants. Influenza virus strains are highly variable and new distinct strains circulate almost every year. A "universal" influenza vaccine inducing long-lasting immunity against all strains of influenza would solve the problem of annual revaccination and would probably improve compliance and vaccination coverage. Numerous candidate vaccines are investigated, which utilize various antigens, such as conserved regions of the surface proteins hemagglutinin and neuraminidase or internal viral proteins. Viral vectors, virus-like particles, DNA vaccines and the use of various adjuvants are discussed and tested as vaccine platforms in order to achieve potent $\mathrm{CD} 4^{+}$and $\mathrm{CD} 8^{+} \mathrm{T}$ cell responses, which are believed to be required for broad protection in addition to antibodies [65].
Universal pneumococcal vaccines would also be very useful, as there are approximately 100 serotypes of $S$. pneumoniae. Currently, vaccine manufacturers try to increase the number of serotypes included in conjugated vaccines, but antibody responses to polysaccharides will probably always be serotype-specific. Several pneumococcal proteins have been identified as potential vaccine candidates. They are highly conserved in all clinically relevant serotypes, and elicit potent immune responses in animal models. Additionally, whole-cell inactivated vaccines, liveattenuated vaccines and combinations of protein and polysaccharide components are investigated [66].

The incidence of herpes zoster is high not only in the elderly, but also in immunocompromised patients, such as after organ or stem cell transplantation, in HIV-positive individuals and in cancer patients, due a decline of cellular immunity. The current vaccine against herpes zoster contains live-attenuated virus and can therefore not be used for these patients due to safety issues [67, 68]. As described above, the efficacy of the vaccine is lower in the very old and wanes over time. Therefore, it is difficult to determine the optimal age for the vaccination, which is also reflected by differing age recommendations in the countries recommending the vaccine. Phase I/II studies demonstrated both the immunogenicity and safety of a novel inactivated vaccine containing the viral glycoprotein $\mathrm{E}$ in combination with the liposome-based AS01B adjuvant system (MPL and QS21) in older adults $[69,70]$ as well as in hematopoietic cell transplant recipients [71] and HIV-patients [72]. Large phase III randomized placebocontrolled trials demonstrated an overall clinical efficacy against herpes zoster of more than $90 \%$ with narrow confidence intervals. Remarkably, the vaccine efficacy was similar in all age groups, even in persons older than 80 years $[73,74]$. This vaccine has recently been licensed in Canada and the US and might replace the live-attenuated herpes zoster vaccine in the future.

\section{New targets for vaccine development}

We still lack vaccines for many pathogens that are of clinical relevance in the elderly. Respiratory syncytial virus (RSV) is a major cause of severe respiratory infection in infants, but usually causes only mild or moderate symptoms in adults. However, older and particularly frail individuals and patients with underlying co-morbidities can experience severe RSV disease. In the UK, an estimated 18,000 hospitalizations and 8400 deaths per year - almost exclusively in the elderly - are caused by RSV and underlying co-morbidity further increases the risk of severe disease [75]. Research on RSV vaccines was slowed down in the past, because a first-generation vaccine used in the 1960s for vaccination of infants was associated with risk for disease enhancement. Several candidate vaccines against RSV based on recombinant proteins, virus-like 
particles, live-attenuated virus or viral vectors are now in clinical development. It is crucial that these novel vaccines are not only developed for the pediatric market, but also include adult and elderly target groups.

There are many more infections affecting the elderly and various vaccine candidates are in pre-clinical or clinical development. One group of pathogens, which attracted special attention over the last years are nosocomial infections. The risk for these infections is high in the elderly, due to more frequent hospitalization and invasive procedures in this age group. Vaccines against bacterial nosocomial infections are highly desirable, as antibiotic resistance is a growing problem, but no such vaccine is currently on the market. The most severe infections are caused by Clostridium difficile, which is the most common cause of nosocomial diarrhea and Staphylococcus aureus, which is responsible for infections of prostheses, catheters or surgical wounds. Two vaccine candidates against $S$. aureus have been clinically tested, but unfortunately did not provide protection [76, 77]. Novel vaccine candidates are now in early stages of development. Most vaccine candidates against $C$. difficile are based on bacterial toxins which are responsible for the clinical symptoms [78]. Vaccines against these and other nosocomial pathogens, such as Klebsiella pneumoniae, Escherichia coli and the fungal pathogen Candida spp. have the potential to substantially reduce healthcare costs and to save many lives [79].

\section{Conclusion}

Older adults are at high risk for infectious diseases and vaccination is an important preventive measure to facilitate healthy aging. Childhood vaccination programs are well-accepted and widely used, but unfortunately awareness for adult vaccination is by far less prominent. Several vaccines against influenza, S. pneumoniae and herpes zoster are available for the elderly and vaccines that are used throughout adulthood, such as tetanus, diphtheria and pertussis, are also relevant for the elderly. The first step towards optimal protection of the elderly is the comprehensive use of existing vaccines. Vaccination recommendations for adults and the elderly differ from country to country. Taking regional differences such as e.g. epidemiological parameters into account is of course necessary for optimal vaccine recommendations, but the diversity of recommendations e.g. throughout Europe can be confusing and might be interpreted as uncertainty. Therefore, increased efforts of harmonization would be desirable [80-82]. Nevertheless, without implementation strategies and sufficient vaccination coverage such guidelines provide only theoretical benefits. Vaccination coverage differs greatly between countries, and data are very difficult to obtain, as many countries do not have centralized databases collecting this information. The WHO goal of $75 \%$ influenza vaccination coverage for older adults ( $>65$ years) until 2014/2015 was not reached by most countries. The UK and the Netherlands reported the highest vaccination rates in Europe (above 70\%), but some other European countries did not even reach $10 \%$ coverage in this age group [83]. Vaccine uptake for other adult vaccinations is not sufficiently documented in most countries and e.g. data on adult vaccination coverage against tetanus and diphtheria is only available for 5 of 29 European countries [84]. Improved vaccines against influenza, pneumococcal disease and herpes zoster have been developed over the last years and continuous effort is put into further increasing their potential to provide broad and long-lasting protection. In addition, vaccines against additional pathogens such as RSV and nosocomial infections could substantially improve health in old age. For the rational design of optimized and novel vaccines for the elderly basic research to understand immunosenescence is essential, and it is of utmost importance that clinical development and testing includes also older age groups.

\section{Abbreviations \\ C. difficile: Clostridium difficile; Candida spp.: Candida species; CAP: Community- acquired pneumonia; Cl: Confidence interval; H: Hemagglutinin; HAl: Hemagglutination inhibition assay; IgM: Immunoglobulin M; ILI: Influenza-like illness; MPL: Monophosphoryl Lipid A; N: Neuraminidase; PCV: Pneumococcal conjugate vaccine; PHN: Post-herpetic neuralgia; PPV: Pneumococcal polysaccharide vaccine; RSV: Respiratory syncytial virus; S. aureus: Staphylococcus aureus; S. pneumoniae: Streptococcus pneumoniae; VZV: Varicella zoster virus; WHO: World Health Organization}

\section{Acknowledgements}

Not applicable

\section{Funding}

This work was supported by the European Union's Seventh Framework Programme [FP7/2007-2013] under Grant Agreement No: 280873 ADITEC.

Availability of data and materials

Not applicable

Authors' contributions

BW wrote the manuscript.

Ethics approval and consent to participate

Not applicable

Consent for publication

Not applicable

Competing interests

The author declares that she has no competing interests.

\section{Publisher's Note}

Springer Nature remains neutral with regard to jurisdictional claims in published maps and institutional affiliations.

Received: 15 August 2017 Accepted: 28 December 2017 Published online: 22 January 2018

References

1. United Nations. World population prospects. 2017. http://esa.un.org/unpd/ wpp. Accessed 30 July 2017.

2. Janssens JP. Pneumonia in the elderly (geriatric) population. Curr Opin Pulm Med. 2005;11:226-30. 
3. Attal N, Deback C, Gavazzi G, Gorwood P, Labetoulle M, Liard F, et al. Functional decline and herpes zoster in older people: an interplay of multiple factors. Aging Clin Exp Res. 2015;27:757-65.

4. European Centre for Disease Prevention and Control: Vaccine schedule. 2017. http://vaccine-schedule.ecdc.europa.eu/Pages/Scheduler.aspx. Accessed 31 Oct 2017

5. Kim DK, Riley LE, Harriman KH, Hunter P, Bridges CB. Advisory Commitee on immunization practices recommended immunization schedule for adults aged 19 years or older-United States, 2017. MMWR Morb Mortal Wkly Rep. 2017:66:136-8.

6. Thompson WW, Shay DK, Weintraub E, Brammer L, Cox N, Anderson L, et al. Mortality associated with influenza and respiratory syncytial virus in the United States. JAMA. 2003;289:179-86.

7. Thompson WW, Shay DK, Weintraub E, Brammer L, Bridges CB, Cox NJ, et al Influenza-associated hospitalizations in the United States. JAMA. 2004;292: $1333-40$.

8. Shaw MW, Xu X, Li Y, Normand S, Ueki RT, Kunimoto GY, et al. Reappearance and global spread of variants of influenza B/Victoria/2/87 lineage viruses in the 2000-2001 and 2001-2002 seasons. Virology. 2002;303:1-8.

9. Trucchi C, Alicino C, Orsi A, Paganino C, Barberis I, Grammatico F, et al Fifteen years of epidemiologic, virologic and syndromic influenza surveillance: a focus on type $B$ virus and the effects of vaccine mismatch in Liguria region, Italy. Hum Vaccin Immunother. 2017;13:456-63.

10. Goodwin K, Viboud C, Simonsen L. Antibody response to influenza vaccination in the elderly: a quantitative review. Vaccine. 2006;24:1159-69.

11. Mysliwska J, Trzonkowski P, Szmit E, Brydak LB, Machala M, Mysliwski A. Immunomodulating effect of influenza vaccination in the elderly differing in health status. Exp Gerontol. 2004;39:1447-58.

12. Yao X, Hamilton RG, Weng NP, Xue QL, Bream JH, Li H, et al. Frailty is associated with impairment of vaccine-induced antibody response and increase in post-vaccination influenza infection in community-dwelling older adults. Vaccine. 2011:29:5015-21.

13. Osterholm MT, Kelley NS, Sommer A, Belongia EA. Efficacy and effectiveness of influenza vaccines: a systematic review and meta-analysis. Lancet Infect Dis. 2012;12:36-44

14. Beyer WE, McElhaney J, Smith DJ, Monto AS, Nguyen-Van-Tam JS, Osterhaus AD. Cochrane re-arranged: support for policies to vaccinate elderly people against influenza. Vaccine. 2013;31:6030-3.

15. De Donato S, Granoff D, Minutello M, Lecchi G, Faccini M, Agnello M, et al. Safety and immunogenicity of MF59-adjuvanted influenza vaccine in the elderly. Vaccine. 1999;17:3094-101.

16. DiazGranados CA, Dunning AJ, Kimmel M, Kirby D, Treanor J, Collins A, et al. Efficacy of high-dose versus standard-dose influenza vaccine in older adults. N Engl J Med. 2014;371:635-45.

17. Holland D, Booy R, de Looze F, Eizenberg P, McDonald J, Karrasch J, et al. Intradermal influenza vaccine administered using a new microinjection system produces superior immunogenicity in elderly adults: a randomized controlled trial. J Infect Dis. 2008;198:650-8.

18. DelGiudice G, Hilbert AK, Bugarini R, Minutello A, Popova O, Toneatto D, et al. An MF59-adjuvanted inactivated influenza vaccine containing a/Panama/ 1999 (H3N2) induced broader serological protection against heterovariant influenza virus strain a/Fujian/2002 than a subunit and a split influenza vaccine. Vaccine. 2006;24:3063-5.

19. Ansaldi F, Bacilieri S, Durando P, Sticchi L, Valle L, Montomoli E, et al. Crossprotection by MF59-adjuvanted influenza vaccine: neutralizing and haemagglutination-inhibiting antibody activity against a(H3N2) drifted influenza viruses. Vaccine. 2008:26:1525-9.

20. Mannino S, Villa M, Apolone G, Weiss NS, Groth N, Aquino I, et al. Effectiveness of adjuvanted influenza vaccination in elderly subjects in northern Italy. Am J Epidemiol. 2012;176:527-33.

21. Iob A, Brianti G, Zamparo E, Gallo T. Evidence of increased clinical protection of an MF59-adjuvant influenza vaccine compared to a nonadjuvant vaccine among elderly residents of long-term care facilities in Italy. Epidemiol Infect. 2005:133:687-93.

22. Kyaw MH, Christie P, Clarke SC, Mooney JD, Ahmed S, Jones IG, et al. Invasive pneumococcal disease in Scotland, 1999-2001: use of record linkage to explore associations between patients and disease in relation to future vaccination policy. Clin Infect Dis. 2003;37:1283-91.

23. Melegaro A, Edmunds WJ, Pebody R, Miller E, George R. The current burden of pneumococcal disease in England and Wales. J Inf Secur. 2006;52:37-48.
24. Centers for Disease Control and Prevention. Prevention of pneumococcal disease: recommendations of the Advisory Committee on Immunization Practices (ACIP). MMWR Recomm Rep. 1997;46:1-24.

25. Bonten MJ, Huijts SM, Bolkenbaas M, Webber C, Patterson S, Gault S, et al. Polysaccharide conjugate vaccine against pneumococcal pneumonia in adults. N Engl J Med. 2015;372:1114-25.

26. Dagan R. Serotype replacement in perspective. Vaccine. 2009;27(Suppl 3):C22-4.

27. Hanquet G, Kissling E, Fenoll A, George R, Lepoutre A, Lernout T, et al. Pneumococcal serotypes in children in 4 European countries. Emerg Infect Dis. 2010;16:1428-39.

28. Elberse KE, van der Heide HG, Witteveen S, van de Pol I, Schot CS, van der Ende A, et al. Changes in the composition of the pneumococcal population and in IPD incidence in The Netherlands after the implementation of the 7valent pneumococcal conjugate vaccine. Vaccine. 2012;30:7644-51.

29. Esposito S, Principi N. Direct and indirect effects of the 13-valent pneumococcal conjugate vaccine administered to infants and young children. Future Microbiol. 2015;10:1599-607.

30. Waight PA, Andrews NJ, Ladhani SN, Sheppard CL, Slack MP, Miller E. Effect of the 13-valent pneumococcal conjugate vaccine on invasive pneumococcal disease in England and Wales 4 years after its introduction: an observational cohort study. Lancet Infect Dis. 2015;15:535-43.

31. Regev-Yochay G, Katzir M, Strahilevitz J, Rahav G, Finn T, Miron D, et al. The herd effects of infant PCV7/PCV13 sequential implementation on adult invasive pneumococcal disease, six years post implementation; a nationwide study in Israel. Vaccine. 2017;35:2449-56.

32. Oxman MN. Herpes zoster pathogenesis and cell-mediated immunity and immunosenescence. J Am Osteopath Assoc. 2009;109:S13-7.

33. Schmader K. Herpes zoster in older adults. Clin Infect Dis. 2001;32:1481-6.

34. Pinchinat $\mathrm{S}$, Cebrian-Cuenca AM, Bricout H, Johnson RW. Similar herpes zoster incidence across Europe: results from a systematic literature review. BMC Infect Dis. 13:2013, 170.

35. Mallick-Searle T, Snodgrass B, Brant JM. Postherpetic neuralgia: epidemiology, pathophysiology, and pain management pharmacology. J Multidiscip Healthc. 2016:9:447-54.

36. Schmader K, Gnann JW Jr, Watson CP. The epidemiological, clinical, and pathological rationale for the herpes zoster vaccine. J Infect Dis. 2008; 197(Suppl 2):S207-15. S207-S215

37. Scott FT, Johnson RW, Leedham-Green M, Davies E, Edmunds WJ, Breuer J. The burden of herpes zoster: a prospective population based study. Vaccine. 2006;24:1308-14.

38. Levin MJ, Oxman MN, Zhang JH, Johnson GR, Stanley H, Hayward AR, et al. Varicella-zoster virus-specific immune responses in elderly recipients of a herpes zoster vaccine. J Infect Dis. 2008;197:825-35.

39. Oxman MN, Levin MJ, Johnson GR, Schmader KE, Straus SE, Gelb LD, et al. A vaccine to prevent herpes zoster and postherpetic neuralgia in older adults. N Engl J Med. 2005;352:2271-84.

40. Schmader KE, Oxman MN, Levin MJ, Johnson G, Zhang JH, Betts R, et al. Persistence of the efficacy of zoster vaccine in the shingles prevention study and the short-term persistence substudy. Clin Infect Dis. 2012;55:1320-8.

41. Morrison VA, Johnson GR, Schmader KE, Levin MJ, Zhang JH, Looney DJ, et al. Long-term persistence of zoster vaccine efficacy. Clin Infect Dis. 2015;60: 900-9.

42. Levin MJ, Schmader KE, Pang L, Williams-Diaz A, Zerbe G, Canniff J, et al. Cellular and Humoral responses to a second dose of herpes zoster vaccine administered 10 years after the first dose among older adults. J Infect Dis. 2016;213:14-22.

43. Bayas JM, Vilella A, Bertran MJ, Vidal J, Batalla J, Asenjo MA, et al. Immunogenicity and reactogenicity of the adult tetanus-diphtheria vaccine. How many doses are necessary? Epidemiol Infect. 2001;127:451-60.

44. Steger MM, Maczek C, Berger P, Grubeck-Loebenstein B, et al. Lancet. 1996; 348:762.

45. Van Damme P, Burgess M. Immunogenicity of a combined diphtheriatetanus-acellular pertussis vaccine in adults. Vaccine. 2004;22:305-8.

46. Kaml M, Weiskirchner I, Keller M, Luft T, Hoster E, Hasford J, et al. Booster vaccination in the elderly: their success depends on the vaccine type applied earlier in life as well as on pre-vaccination antibody titers. Vaccine. 2006;24:6808-11.

47. Launay O, Toneatti C, Bernede C, Njamkepo E, Petitprez K, Leblond A, et al. Antibodies to tetanus, diphtheria and pertussis among healthy adults vaccinated according to the French vaccination recommendations. Hum vaccin. 2009;5:341-6. 
48. Weinberger B, Schirmer M, Matteucci GR, Siebert U, Fuchs D, GrubeckLoebenstein B. Recall responses to tetanus and diphtheria vaccination are frequently insufficient in elderly persons. PLoS One. 2013;8:e82967.

49. Grasse M, Meryk A, Schirmer M, Grubeck-Loebenstein B, Weinberger B. Booster vaccination against tetanus and diphtheria: insufficient protection against diphtheria in young and elderly adults. Immun Ageing. 2016;13:26

50. Weinberger B. Adult vaccination against tetanus and diphtheria: the European perspective. Clin Exp Immunol. 2017;187:93-9.

51. Weinberger B, Keller M, Fischer KH, Stiasny K, Neuner C, Heinz FX, et al. Decreased antibody titers and booster responses in tick-borne encephalitis vaccinees aged 50-90 years. Vaccine. 2010;28:3511-5.

52. Stiasny K, Aberle JH, Keller M, Grubeck-Loebenstein B, Heinz FX. Age affects quantity but not quality of antibody responses after vaccination with an inactivated flavivirus vaccine against tick-borne encephalitis. PLoS One. 2012; $7:$ :34145

53. Rendi-Wagner P, Tobias J, Moerman L, Goren S, Bassal R, Green M, et al. The seroepidemiology of Bordetella pertussis in Israel-estimate of incidence of infection. Vaccine. 2010;28:3285-90.

54. Ridda I, Yin JK, King C, Raina MC, Mclntyre P. The importance of pertussis in older adults: a growing case for reviewing vaccination strategy in the elderly. Vaccine. 2012;30:6745-52.

55. Gil A, Oyaguez I, Carrasco P, Gonzalez A. Hospital admissions for pertussis in Spain, 1995-1998. Vaccine. 2001;19:4791-4.

56. Halperin SA, Scheifele D, de Serres G, Noya F, Meekison W, Zickler P, et al. Immune responses in adults to revaccination with a tetanus toxoid, reduced diphtheria toxoid, and acellular pertussis vaccine 10 years after a previous dose. Vaccine. 2012;30:974-82.

57. Taylor DN, Pollard RA, Blake PA. Typhoid in the United States and the risk to the international traveler. J Infect Dis. 1983;148:599-602.

58. Hennessy S, Liu Z, Tsai TF, Strom BL, Wan CM, Liu HL, et al. Effectiveness of live-attenuated Japanese encephalitis vaccine (SA14-14-2): a case-control study. Lancet. 1996;347:1583-6.

59. Haynes $L$. The effect of aging on cognate function and development of immune memory. Curr Opin Immunol. 2005;17:476-9.

60. Haynes L, Eaton SM, Burns EM, Randall TD, Swain SL. CD4 T cell memory derived from young naive cells functions well into old age, but memory generated from aged naive cells functions poorly. Proc Natl Acad Sci U S A. 2003;100:15053-8.

61. Stoffel M, Lievens M, Dieussaert I, Martin I, Andre F. Immunogenicity of Twinrix in older adults: a critical analysis. Expert Rev Vaccines. 2003;2:9-14.

62. Wolters B, Junge U, Dziuba S, Roggendorf M. Immunogenicity of combined hepatitis $a$ and $B$ vaccine in elderly persons. Vaccine. 2003;21:3623-8.

63. Fisman DN, Agrawal D, Leder K. The effect of age on immunologic response to recombinant hepatitis B vaccine: a meta-analysis. Clin Infect Dis. 2002;35:1368-75.

64. Rafferty E, Duclos P, Yactayo S, Schuster M. Risk of yellow fever vaccineassociated viscerotropic disease among the elderly: a systematic review. Vaccine. 2013;31:5798-805

65. Wiersma LC, Rimmelzwaan GF, de Vries RD. Developing universal influenza vaccines: hitting the nail, not just on the head. Vaccines (Basel). 2015;3:239-62.

66. Feldman C, Anderson R. Review: current and new generation pneumococcal vaccines. J Inf Secur. 2014;69:309-25.

67. Harpaz R, Ortega-Sanchez IR, Seward JF. Prevention of herpes zoster: recommendations of the advisory committee on immunization practices (ACIP). MMWR Recomm Rep. 2008;57:1-30.

68. Hales CM, Harpaz R, Ortega-Sanchez I, Bialek SR. Update on recommendations for use of herpes zoster vaccine. MMWR Morb Mortal Wkly Rep. 2014;63:729-31.

69. Leroux-Roels I, Leroux-Roels G, Clement F, Vandepapeliere P, Vassilev V, Ledent $E$, et al. A phase $1 / 2$ clinical trial evaluating safety and immunogenicity of a varicella zoster glycoprotein e subunit vaccine candidate in young and older adults. J Infect Dis. 2012;206:1280-90.

70. Chlibek R, Bayas JM, Collins H, de la Pinta ML, Ledent E, Mols JF, et al. Safety and immunogenicity of an AS01-adjuvanted varicella-zoster virus subunit candidate vaccine against herpes zoster in adults $>=50$ years of age. J Infect Dis. 2013;208:1953-61.

71. Stadtmauer EA, Sullivan KM, Marty FM, Dadwal SS, Papanicolaou GA, Shea TC, et al. A phase $1 / 2$ study of an adjuvanted varicella-zoster virus subunit vaccine in autologous hematopoietic cell transplant recipients. Blood. 2014;124:2921-9.

72. Berkowitz EM, Moyle G, Stellbrink HJ, Schurmann D, Kegg S, Stoll M, et al. Safety and immunogenicity of an adjuvanted herpes zoster subunit candidate vaccine in HIV-infected adults: a phase 1/2a randomized, placebo-controlled study. J Infect Dis. 2015;211:1279-87.

73. Lal H, Cunningham AL, Godeaux O, Chlibek R, Diez-Domingo J, Hwang SJ, et al. Efficacy of an adjuvanted herpes zoster subunit vaccine in older adults. N Engl J Med. 2015;372:2087-96.

74. Cunningham AL, Lal H, Kovac M, Chlibek R, Hwang SJ, Diez-Domingo J, et al. Efficacy of the herpes zoster subunit vaccine in adults 70 years of age or older. N Engl J Med. 2016;375:1019-32.

75. Fleming DM, Taylor RJ, Lustig RL, Schuck-Paim C, Haguinet F, Webb DJ, et al. Modelling estimates of the burden of respiratory Syncytial virus infection in adults and the elderly in the United Kingdom. BMC Infect Dis. 2015;15:443.

76. Shinefield H, Black S, Fattom A, Horwith G, Rasgon S, Ordonez J, et al. Use of a Staphylococcus Aureus conjugate vaccine in patients receiving hemodialysis. N Engl J Med. 2002;346:491-6.

77. Fowler VG, Allen KB, Moreira ED, Moustafa M, Isgro F, Boucher HW, et al. Effect of an investigational vaccine for preventing Staphylococcus Aureus infections after cardiothoracic surgery: a randomized trial. JAMA. 2013;309:1368-78.

78. Swanson KA, Schmitt HJ, Jansen KU, Anderson AS. Adult vaccination. Hum Vaccin Immunother. 2015;11:150-5.

79. Cross AS, Chen WH, Levine MM. A case for immunization against nosocomial infections. J Leukoc Biol. 2008;83:483-8.

80. Michel JP, Chidiac C, Grubeck-Loebenstein B, Johnson RW, Lambert PH, Maggi $S$, et al. Advocating vaccination of adults aged 60 years and older in Western Europe: statement by the joint vaccine working Group of the European Union Geriatric Medicine Society and the International Association of Gerontology and Geriatrics-European Region. Rejuvenation Res. 2009;12:127-35.

81. Michel JP, Lang PO, Baeyens JP. Flu vaccination policy in old adults: need for harmonization of national public health recommendations throughout Europe. Vaccine. 2009;27:182-3.

82. Esposito S, Bonanni P, Maggi S, Tan L, Ansaldi F, Lopalco PL, et al. Recommended immunization schedules for adults: clinical practice guidelines by the Escmid vaccine study group (EVASG), European geriatric medicine society (EUGMS) and the world Association for Infectious Diseases and Immunological Disorders (WAidid). Hum Vaccin Immunother. 2016;12:1777-94.

83. European Centre for Disease Prevention and Control. Seasonal influenza vaccination in Europe. Vaccination recommendations and coverage rates in the EU member states for eight influenza seasons: 2007-2008 to 2014-2015. 2017. https://ecdc.europa.eu/sites/portal/files/documents/influenzavaccination-2007\%E2\%80\%932008-to-2014\%E2\%80\%932015.pdf. Accessed 27 July 2017.

84. Kanitz EE, Wu LA, Giambi C, Strikas RA, Levy-Bruhl D, Stefanoff P, et al. Variation in adult vaccination policies across Europe: an overview from VENICE network on vaccine recommendations, funding and coverage. Vaccine. 2012:30:5222-8.

\section{Submit your next manuscript to BioMed Central and we will help you at every step:}

- We accept pre-submission inquiries

- Our selector tool helps you to find the most relevant journal

- We provide round the clock customer support

- Convenient online submission

- Thorough peer review

- Inclusion in PubMed and all major indexing services

- Maximum visibility for your research

Submit your manuscript at www.biomedcentral.com/submit 